\title{
BMJ Open Functional health literacy in a population-based sample in Florence: a cross-sectional study using the Newest Vital Sign
}

Guglielmo Bonaccorsi, Vieri Lastrucci, Virginia Vettori, Chiara Lorini, on behalf of the Florence Health Literacy Research Group

To cite: Bonaccorsi G, Lastrucci V, Vettori V, et al. Functional health literacy in a population-based sample in Florence: a crosssectional study using the Newest Vital Sign. BMJ Open 2019;9:e026356. doi:10.1136/ bmjopen-2018-026356

- Prepublication history and additional material for this paper are available online. To view, please visit the journal (http:// dx.doi.org/10.1136/bmjopen2018-026356).

Received 28 August 2018 Revised 19 February 2019 Accepted 28 May 2019

\section{Check for updates}

(C) Author(s) (or their employer(s)) 2019. Re-use permitted under CC BY-NC. No commercial re-use. See rights and permissions. Published by BMJ.

Department of Health Sciences, University of Florence, Florence, Italy

Correspondence to

Dr Vieri Lastrucci;

vieri.lastrucci@gmail.com

\section{ABSTRACT}

Objectives To assess the level of functional health literacy $(\mathrm{HL})$ and its antecedents and consequences in an adult population-based sample, using the Italian version of Newest Vital Sign (NVS-IT).

Design Cross-sectional study.

Setting General population.

Participants 984 people were randomly selected from the resident registers of 11 general practitioners; a total of $452(46.2 \%)$ of the selected people completed the study. Inclusion criteria were the following: 18-69 years of age and Italian speaking. Exclusion criteria included cognitive impairment, severe psychiatric diseases and end-stage diseases.

Outcome measures HL levels as assessed by the NVS-IT and the following potential HL predictors and consequences were assessed using logistic regression models: sociodemographic characteristics, body mass index, presence of long-term illnesses, self-reported health status, health services use in the last 12 months.

Results High likelihood of limited HL, possibility of limited $\mathrm{HL}$ and adequate $\mathrm{HL}$ were found in $11.5 \%, 24.6 \%$ and $63.9 \%$ of the sample, respectively. The results of the multivariate logistic model for the antecedents showed that the risk of having high likelihood or possibility of limited HL levels increases with age (OR 1.07, 95\% Cl 1.05 to 1.09 ), lower educational level (OR $4.03 ; 95 \% \mathrm{Cl} 3.41$ to 7.49 ) and with worse financial situation (OR 1.64; $95 \% \mathrm{Cl}$ 1.17 to 2.63). As far as health outcomes are concerned, $\mathrm{HL}$ resulted to be positively associated with self-reported health status (OR 2.25, $95 \% \mathrm{Cl} 1.75$ to 2.75 ).

Conclusions Findings show a good level of functional $\mathrm{HL}$ in the population. However, older, less educated and poorer population groups showed to have a higher likelihood of suffering from limited or inadequate HL. Efforts should be made to design and implement public health policies and interventions tailored to different HL levels.

Trial registration number CEAVC:10113.

\section{INTRODUCTION}

Health literacy (HL) is closely linked to empowerment and concerns the knowledge and competences of individuals necessary for meeting the complex health demands of

\section{Strengths and limitations of this study}

This study provides a measure of functional health literacy in a population-based sample in Florence.

- The population-based sample was obtained with a combination of convenience and probability sampling procedures.

Differently from other studies, the Italian version of the Newest Vital Sign (NVS-IT) was administered through phone-interview.

- The concordance between face-to-face and phone-administered NVS-IT interviews was pretested on 35 participants.

- Predictors and outcomes of NVS-IT were analysed using logistic regression models, with results quite different from other published studies.

modern society. HL can be defined as 'the ability of citizens to make sound decisions concerning health in daily life-at home, at work, in healthcare, at the market place and in the political arena'. ${ }^{1}$ HL has been identified as a priority area for policy action in the strategy of WHO and in the policy documents of the European Commission. ${ }^{2}{ }^{3}$ Indeed, several studies have shown that limited HL among adults is a major public health problem; limited HL has been shown to be associated with several health-related consequences such as adverse health behaviours and outcomes, increased mortality risk, poor management of chronic diseases, lower use of preventive services and higher healthcare costs. ${ }^{4-6}$ As far as predictors of HL (ie, antecedents) are concerned, several proximal (ie, personal and situational) and distal (ie, societal and environmental) factors have been proposed. ${ }^{4-6}$

Functional HL is one dimension of the concept of HL that entails the ability to interpret, calculate and act on oral and written information in healthcare settings. Several 
tools have been proposed for assessing functional $\mathrm{HL}^{78}$ however most of them take several minutes to administer. This is an issue that poses barriers in their use outside of academic contexts, especially for time-demanding clinical settings or for interventions in the general population. In 2005, the Newest Vital Sign (NVS) was proposed as a brief and easy to administer screening tool for measuring HL. ${ }^{9}$ The NVS is a six-item screening tool that requires the participants to interpret the information presented on a nutrition label; it assesses reading, numeracy and comprehension skills. The NVS demonstrated a high degree of correlation with other functional HL measures. ${ }^{10}$

The NVS was originally developed and is still mainly used in the clinical setting. ${ }^{911-13}$ To date, there have been only limited studies on HL assessed with the NVS and its antecedents and consequences carried out in the general population. Furthermore, since most studies have been conducted in clinical settings, ${ }^{9}{ }^{11-13}$ the assessed individuals have specific demographic and characteristics that pertain to the environment of the studies; moreover, the included samples typically tend to under-represent socially disadvantaged groups. ${ }^{14}$

In 2011, the European health literacy survey (HLS-EU) was the first study assessing HL at the general population level in several European countries. ${ }^{5}$ The HL measure used in this study was specifically designed for the study (ie, HLS-EU-Q47), however translated versions of the NVS were also included in the study. The study reported that around $12 \%$ of the sample was very likely to have limited literacy. Age and education resulted to be associated with NVS scores in all the countries included in the study. However, several causal inferences for HL measured with the NVS were not examined as the NVS tool was mainly used for comparing and validating the newly developed HL measure. Furthermore, in this study the Italian population was not included. A study recently conducted in Portugal found that people with limited HL were significantly older and less educated, ${ }^{15}$ and a study conducted in Australian population also reported male sex, foreign nationality and socioeconomic status as predictors of inadequate HL. ${ }^{16}$ As regard HL consequences, low HL levels were reported to be associated with a higher risk of chronic diseases and a lower access to primary care services. ${ }^{16}$ As far as the Italian population is concerned, the Italian version of the NVS (NVS-IT) was developed from the European version used in the HLS-EU survey and its validation study was recently published. ${ }^{17}{ }^{18}$ To date, few studies have been conducted using the NVS-IT. However, these studies were either conducted with small convenience samples or in specific clinical contexts. ${ }^{19} 20$

In the literature, few studies have used the NVS to investigate HL and its associations in the general population. ${ }^{515} 1621$ Furthermore, as HL and its antecedents and consequences may vary from one country to another, results are not generalisable. In order to deepen knowledge on HL in the general population and to provide reliable and specific information on the Italian population, a research project that aimed at assessing HL levels in a population-based sample, and to validate different HL measures in Italian language was carried out. This study is the second output of this research project, of which a full protocol has been published and detailed elsewhere ${ }^{22}{ }^{23}$ Specifically, the aim of the present study was to evaluate the levels and the associations of HL in an adult general population using the NVS-IT.

\section{METHODS}

For more detailed information regarding the methods, the reader is referred to the study protocol published elsewhere. ${ }^{22}$ The study was conducted according to the principles described in the Declaration of Helsinki.

\section{Study population and sampling criteria}

This is a cross-sectional study that was carried out in a population-based sample. Participants were randomly selected from a list of residents available from the registers of 11 general practitioners (GPs) working in primary healthcare centres of the municipality of Florence. According to the regulations of the National Healthcare System and the Constitution of the Italian Republic, in Italy every Italian and Foreign resident over the age of 18 has to be registered in a general practice, and people are enrolled in the general practices according to their place of residence (percentage of resident population registered $98.8 \%$ ). This sampling method was chosen with the aim of increasing the population participation rate as the invitation letter was jointly signed by the general practitioners and the researcher in charge of the study. ${ }^{24}$

The GPs were recruited using convenience criteria. All the GPs of the municipality of Florence were invited to join the study by both the Provincial Medical Council and the University Hospital of Florence. A total of 11 GPs based in different districts of Florence were recruited on a firstcome basis. The number of GPs recruited in the study was increased from what had been originally proposed in the study protocol (ie, $n=8$ ) in order to extend the geographical coverage of the study. ${ }^{22}$ The recruited general practices were based in the city centre and in the inner and outer suburban areas of Florence.

Each GP selected 80 people from its register through a random number generator. Inclusion criteria were the following: 18-69 years of age and Italian speaking (since the survey was conducted in Italian only). Exclusion criteria included cognitive impairment, severe psychiatric diseases and end-stage diseases. Inclusion and exclusion criteria were applied by each GP independently.

\section{Procedures: data collection and measurements}

Data were collected between February 2017 and December 2017. Each selected person was contacted via postal mail. The selected people received an information sheet signed by both the GP and the person in charge of the study. The letter also included a short description of the study, an invitation to participate and a consent form. Participants were asked to sign the consent form 
and return it via mail to the researchers in charge. The mail also contained the nutritional label of the NVS-IT designed to be easily readable (ie, large font size and linespacing). After receipt of the signed consent forms, the participants were contacted over phone for the computer-assisted interview. If the consent form was not received within 2 weeks, a follow-up phone call was made by the research group. The phone call served to clarify any questions and to identify and support people with difficulties in completing the consent form (eg, reading difficulties). Nine interviewers conducted the phone interviews. A shared written protocol on how to conduct the interview was followed in order to standardise the interviews and to limit interviewer bias. Each participant was randomly assigned to one of the nine interviewers and contacted a maximum of six times before being considered unreachable. The whole interview took about 20-25 min.

The following 'antecedents' variables were collected: sex, birth year, nationality, number of years living in Italy (for those who were born abroad), educational level, marital status, number of family and non-family members living in the same household. Furthermore, the antecedents variables also included whether one has ever received training or is/has been employed in the field of healthcare, employment status (currently having a paid job), financial situation and whether a family member or a friend normally accompanies him/her to medical appointments.

As for health outcomes, the following variables were investigated: self-reported health status (excellent, very good, good, so-so/fair, bad), self-reported weight and height to calculate the body mass index (BMI), health services used in the last 12 months (number of doctor visits, hospital admissions, emergency department visits). Responses were coded as follows: 0, 1-2 times, 3-5 times, 6 times or more, do not know, refusal). The use of other healthcare services in the 12 last months was also investigated (overall number of dentist, physiotherapist, psychologist, dieticians and optician visits). To measure health status, participants were also asked about longterm illnesses (illnesses that have lasted or are expected to last for at least 6 months), coded in five categories: yes, more than one; yes, one; no; do not know; refusal.

The NVS-IT consists of an ice cream nutrition label, with seven associated questions that measure literacy and numeracy. ${ }^{18}$ It produces a final score ranging from 0 to 6 , allowing participants to be classified into three categories-high likelihood of limited HL (score: $0-1$ ), possibility of limited HL (score: 2-3) and adequate HL (score: 4-6). To the best or our knowledge, no published studies have reported NVS data collected through telephone interviews; for this reason, the concordance between face-to-face and phone-administered NVS-IT interviews was pretested in a convenience sample of 35 participants of different age, sex and educational level. This sample size was established considering a number of participants of about 5 times the number of the items of the tool (ie, NVS-IT) as suggested by Parker et al. ${ }^{25}$ Furthermore, this sample size was chosen in line with the sample size requirements for estimating the value of intraclass correlation coefficient (ICC) and the Cohen's $\kappa$ agreement test as proposed by Bujanga and Baharum. ${ }^{26} 27$

For testing the concordance between face-to-face and phone-administered NVS-IT, two study arms were defined. In both arms, the participants received both the telephone and the face-to-face interview with an interval period of 10 days. The two arms differed only in the sequence in which the participants received the telephone or the face-to-face interview first. Each participant was randomly assigned to one of the two arms.

\section{Statistical analysis}

Collected variables were tested for normality using Kolmogorov-Smirnov test.

For all the analyses, participants with high likelihood of limited HL and those with possibility of limited HL were grouped together in a single group, referred to 'inadequate and at-risk HL' and compared with the adequate HL group. ${ }^{16}$

In the pretesting phase, NVS-IT scores obtained using the telephonic and face-to-face interviews were compared. Specifically, between the two arms, NVS-IT score distributions were compared both at T0 and at T1 using unpaired Student's t-test or Mann-Whitney U test; within the two arms, NVS-IT score distributions at $\mathrm{T} 0$ were compared with respect to those obtained at T1 using paired Student's t-test or Wilcoxon paired test for matched data. ICC (two-way random, single measures, absolute agreement) was calculated in order to assess the correlation between the NVS scores obtained at T0 and $\mathrm{T} 1$, in the whole sample and in the two subgroups (telephonic vs face-to-face interviews; face-to-face vs telephonic interviews); $\chi 2$ test was used to evaluate the association between the classification into two groups of HL (inadequate and at-risk HL vs adequate HL) and the mode of administration at $\mathrm{T} 0$ and at $\mathrm{T} 1$, respectively. Moreover, Cohen's $\kappa$ was calculated to assess the agreement in the classification into two groups of HL (inadequate and at-risk HL vs adequate HL) at T0 and $\mathrm{T} 1$, in the whole sample and in the two subgroups (telephonic vs face-to-face interviews; face-to-face vs telephonic interviews). For Cohen's $\kappa$ and ICC, the following interpretation was considered: poor agreement for values lower than 0.40 , fair agreement for values comprised between 0.40 and 0.59 , good agreement for values comprised between 0.60 and 0.74 , excellent agreement for values comprised between 0.75 and $1.00 .^{28}$

The internal consistency of NVS-IT was assessed through the Cronbach's $\alpha$ coefficient.

A descriptive univariate analysis using $\chi^{2}$ test for categorical and ordinal data and unpaired Student's t-test, analysis of variance or the corresponding non-parametric tests (Mann-Whitney U test or Kruskal-Wallis test) for 
continuous data were performed in order to evaluate significant associations between NVS-IT categories and all the variables considered. To analyse the predictors of HL, all the evaluated antecedents (ie, sex, age, nationality, educational level, marital status, number of family and non-family members in the same household, experience in the field of healthcare, employment status, financial situation and family or friend support) were entered into a first multivariate logistic regression model considering the NVS-IT categories ('inadequate and at-risk HL' vs 'adequate HL') as the dependent variable; a backward stepwise procedure was applied to obtain the final model of significant predictors of HL.

NVS-IT as a predictor of health-related outcomes (self-reported health status, BMI categories, health services used in the last 12 months) was tested in several multivariate logistic regression models. Specifically, health related outcomes significantly associated with NVS-IT categories at the univariate analysis were entered into different multivariate logistic regression models as dependent variables (one for each), dichotomising the categories as follows: 'excellent, very good or good' versus 'so-so/fair or bad' for self-reported health status; 'underweight or normal' versus 'overweight or obese' for BMI categories; 'never' versus 'one or more times' for health services used in the last 12 months. In each model, all the evaluated predictors (antecedents) of NVS-IT categories were included as covariates. Each multivariate regression model was performed using a backward stepwise procedure. For each analysis, an $\alpha$ level of 0.05 was considered as significant. The statistical softwares IBM SPSS Statistics for Windows, V.25.0 and StataIC V.11 (StataCorp) were used for data analyses.

\section{Patient and public involvement}

The study population or the public were not involved in the conceptualisation or carrying out of this research.
RESULTS

\section{Pretesting phase: face-to-face versus phone-administered} interviews

Thirty-five volunteers $(48.6 \%$ females; mean age: $44.3 \pm 15.8$ years; $11.4 \%$ with less than high school degree and $45.7 \%$ with high school degree) were included in the pretesting phase, with a similar distribution in the two arms: for 18 participants (51.4\%), NVS-IT was administered face-to-face first. Both mean age and educational level were not significantly different between the two arms (respectively, Mann-Whitney $\mathrm{U}$ test: $\mathrm{p}=0.946, \chi^{2}$ test: $p=0.07)$. At T0, NVS-IT score for the face-to-face administered interviewed was $4.11 \pm 1.66$ while for the phone-administered interviewed it was $4.76 \pm 1.43$, without statistically significant differences (Mann-Whitney U test: $\mathrm{p}=0.207$ ). At $\mathrm{T} 0$, the classification into two groups of $\mathrm{HL}$ (inadequate and at-risk HL; adequate HL) did not significantly differ in the two arms $\left(\chi^{2}\right.$ test, $\left.\mathrm{p}=0.328\right)$ (table 1$)$.

At T1, with the different administration, both groups increased the mean NVS-IT scores (figure 1) (from $4.11 \pm 1.66$ to $4.67 \pm 1.49$ and from $4.76 \pm 1.43$ to $5.10 \pm 1.43$ ) but not in a statistically significant way (Wilcoxon paired test for matched data: $\mathrm{p}=0.065$ and $\mathrm{p}=0.160$, respectively). At T1, the NVS-IT scores and the classification into two groups of HL (inadequate and at-risk HL; adequate HL) were not significantly different between the two arms as well (Mann-Whitney $\mathrm{U}$ test: $\mathrm{p}=0.335 ; \chi^{2}$ test, $\mathrm{p}=0.939$ ) (table 1).

Two scatter plots for the NVS score are reported in figure 1 . The ICC in the whole sample, in group I (face-toface vs telephone interview) and in group II (telephone vs face-to-face interview) were $0.837(\mathrm{p}<0.001), 0.824$ $(\mathrm{p}<0.001)$ and $0.843(\mathrm{p}<0.001)$, respectively. Therefore, the agreement was excellent both in the whole sample and in the two subgroups. As far as the classification into two groups of HL (inadequate and at-risk HL; adequate

Table 1 Pretesting phase: classification into two groups of $\mathrm{HL}$ (inadequate and at-risk HL; adequate $\mathrm{HL}$ ) at T0 and T1

\begin{tabular}{|c|c|c|c|c|c|c|}
\hline & & & \multicolumn{2}{|c|}{ First administration (T0) } & \multirow[b]{2}{*}{ Total } & \multirow[b]{2}{*}{$\begin{array}{l}\text { Cohen's к (p } \\
\text { value) }\end{array}$} \\
\hline & & & $\begin{array}{l}\text { Inadequate } \\
\text { and at-risk HL }\end{array}$ & $\begin{array}{l}\text { Adequate } \\
\mathrm{HL}\end{array}$ & & \\
\hline \multirow{2}{*}{ Whole sample } & $\begin{array}{l}\text { Second } \\
\text { administration (T1) }\end{array}$ & Adequate $H L$ & 6 & 23 & 29 & \multirow{2}{*}{$0.471(0.003)$} \\
\hline & Total & & 11 & 24 & 35 & \\
\hline $\begin{array}{l}\text { Group I (face-to-face vs } \\
\text { telephone) }{ }^{\star} \dagger\end{array}$ & Total & & 7 & 11 & 18 & $0.478(0.017)$ \\
\hline \multirow{3}{*}{$\begin{array}{l}\text { Group II (telephone vs } \\
\text { face-to-face) }{ }^{\star \dagger}\end{array}$} & \multirow{2}{*}{$\begin{array}{l}\text { Second } \\
\text { administration (T1) }\end{array}$} & Inadequate and at-risk $H L$ & 2 & 1 & 3 & \multirow[t]{3}{*}{$0.463(0.05)$} \\
\hline & & Adequate $H L$ & 2 & 12 & 14 & \\
\hline & Total & & 4 & 13 & 17 & \\
\hline
\end{tabular}

Whole sample and two subgroups (face-to-face vs telephone interview; telephone vs face-to-face interview).

${ }^{*}$ Distribution at T0 (group I vs group II): $\chi^{2}$ test $=0.957$ ( $\left.1 \mathrm{df}\right) ; p=0.328$.

†Distribution at T1 (group I vs group II): $\chi^{2}$ test $=0.006(1 \mathrm{df}) ; p=0.939$.

$\mathrm{HL}$, health literacy. 

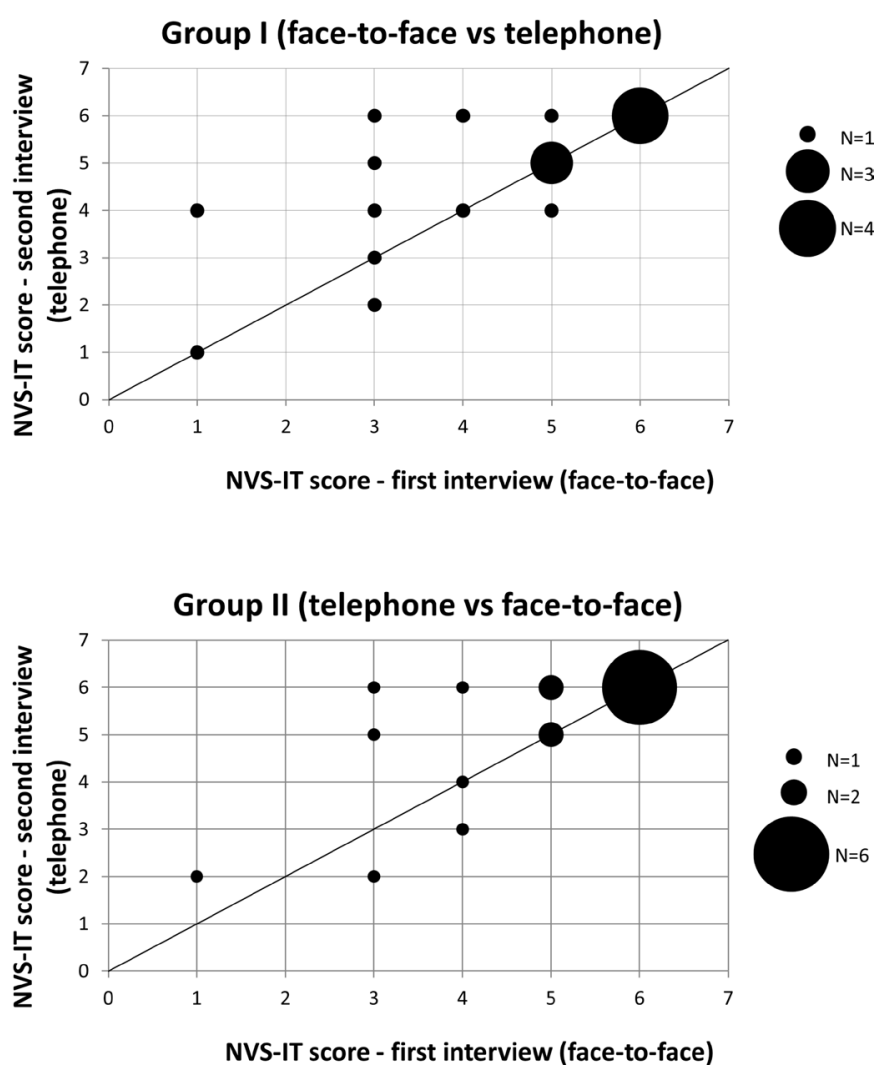

Figure 1 Scatter plots of the Italian version of Newest Vital Sign (NVS-IT) scores at T0 and T1 of the pretesting phase.

HL) is concerned, the agreement in the whole sample and in the two subgroups was fair (Cohen's $\kappa$ values were $0.471, p=0.003 ; 0.478, p=0.017$ and $0.463, p=0.05$ in the whole sample, in group I and in group II, respectively) (table 1).

\section{Sample characteristics}

A total of 984 individuals were invited to participate in the study, of which 493 agreed to be interviewed (50.1\%) and $454(46.1 \%)$ were effectively interviewed. As far as non-participation reasons were concerned, $151(15.3 \%$ of the total sample) people refused to participate, 340 (34.5\% of the total sample) people did not respond to any contact attempts, and a further 39 (4\% of the total sample) people initially agreed to be interviewed, but subsequently it was not possible to arrange an interview. Non-participants resulted to be on average 2 years younger than participants $(51.2 \pm 11.8$ and $53.3 \pm 11.7$ years, respectively). No significant sex differences emerged between participants and non-participants. Two interviews resulted to have several data missing and were excluded from the study; a total sample of 452 participants were considered for the analyses.

The participants' characteristics are presented in table 2 . The mean age of the sample was $53.2 \pm 11.7$ years and males represented $41.2 \%$ of the sample. Participants with bachelor's degree or higher represented the $41.2 \%$ of the sample, and $17.3 \%$ of the participants easily got at the end of the month with their income.
Health literacy distribution and its associations with antecedents and consequences

The Cronbach's $\alpha$ coefficient for the NVS-IT in this study was 0.741 . The NVS-IT score was J-shaped (figure 2), with mean value of $4.05 \pm 1.88$ and median value of $4 ; 25 \%$ of the participants presented NVS-IT scores lower than 3 . As far as the HL levels distribution in the sample was concerned, high likelihood of limited HL, possibility of limited HL and adequate HL were found in the $11.5 \%$, $24.6 \%$ and $63.9 \%$ of the sample, respectively.

HL was significantly associated with the following variables (table 2): age, educational level, employment status, financial situation, number of family and non-family members in the household, self-reported health status and the presence of long-term illnesses. Specifically, the percentage of subjects with high likelihood of limited HL was higher in the lower educational level, in the worse health status, in unemployed or retired people, in people with more than one long-term illnesses, in people living with another person and in people with a worse financial situation.

All the potential predictors of HL were included in the first multivariate logistic regression model. The final multivariate logistic regression model for the antecedents was obtained thought backward stepwise method (table 3). In particular, the risk of having inadequate and at-risk HL levels increased with age (OR 1.07, $\mathrm{p}<0.001)$, with a lower educational level (OR 2.02, $\mathrm{p}=0.004$ and OR 4.03; $\mathrm{p}<0.001$ comparing the bachelor's degree and higher educational level group with high school degree group or with less than a high school diploma group, respectively) and with a worse financial situation (OR $1.64, \mathrm{p}=0.041$ ).

As far as health outcomes were concerned, HL resulted to be significantly associated only with self-reported health status at the univariate analysis. Besides HL, age, educational level, nationality, long-term illness, employment and financial status resulted to be significantly associated with self-reported health status (data reported in the online supplementary file). All the potential predictors of self-reported health status were included in the first multivariate logistic regression model with self-reported health status as the dependent variable. Results of the final model are reported in table 4. Participants with inadequate and at-risk HL were about two times more likely than participants with adequate HL to report a worse self-reported health status (OR 2.25, $\mathrm{p}=0.002$ ). The presence of one or more long-term illnesses and a worse financial situation remained significantly associated with a worse self-reported health status in the final model (table 4).

\section{DISCUSSION}

The aim of this study was to assess the level of functional HL in a population-based sample using the NVS-IT and explore the association of functional HL with antecedents and health outcomes. ${ }^{18}$ Our results showed the 
Table 2 Sociodemographic characteristics and Newest Vital Sign $(n=452) \dagger$

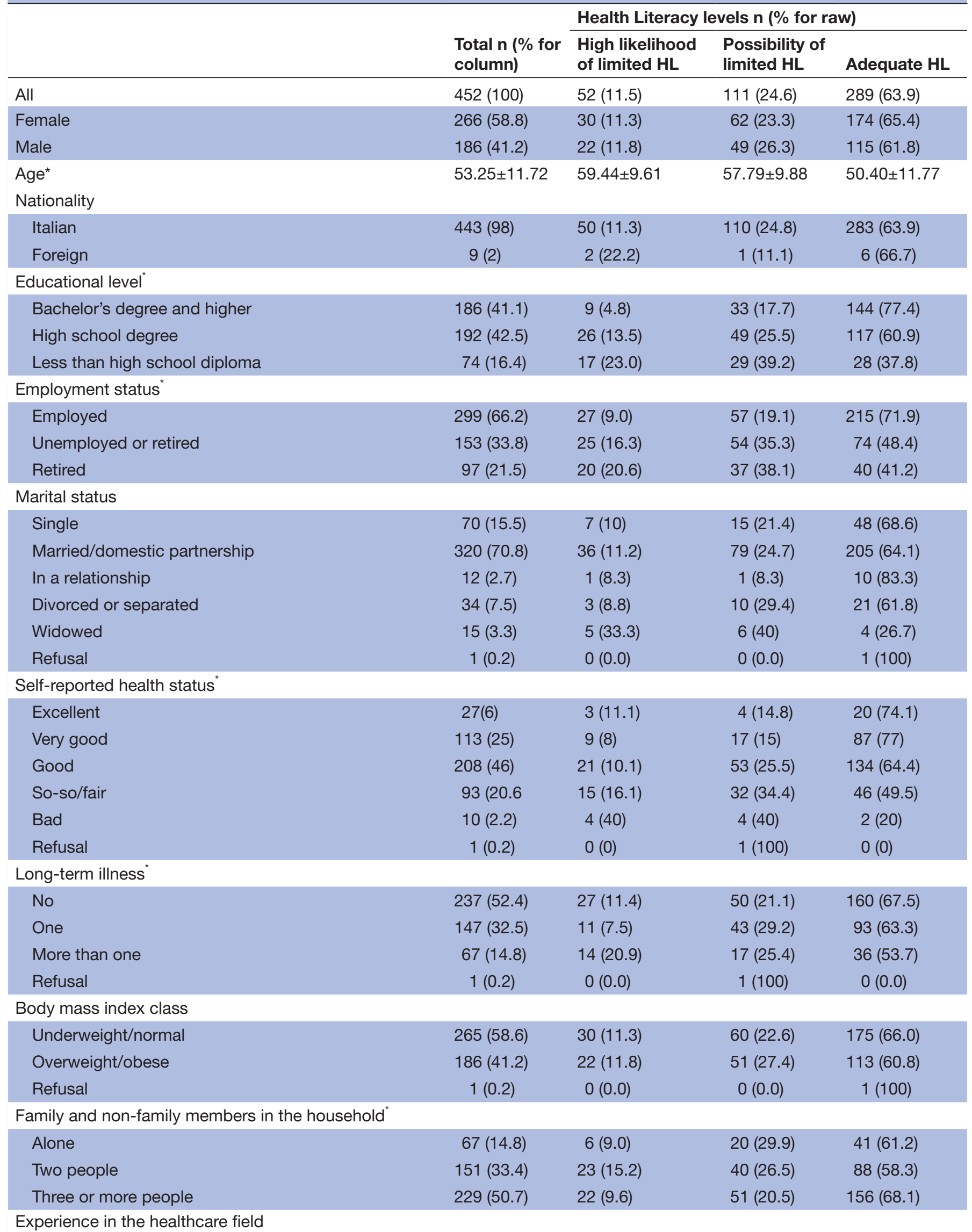




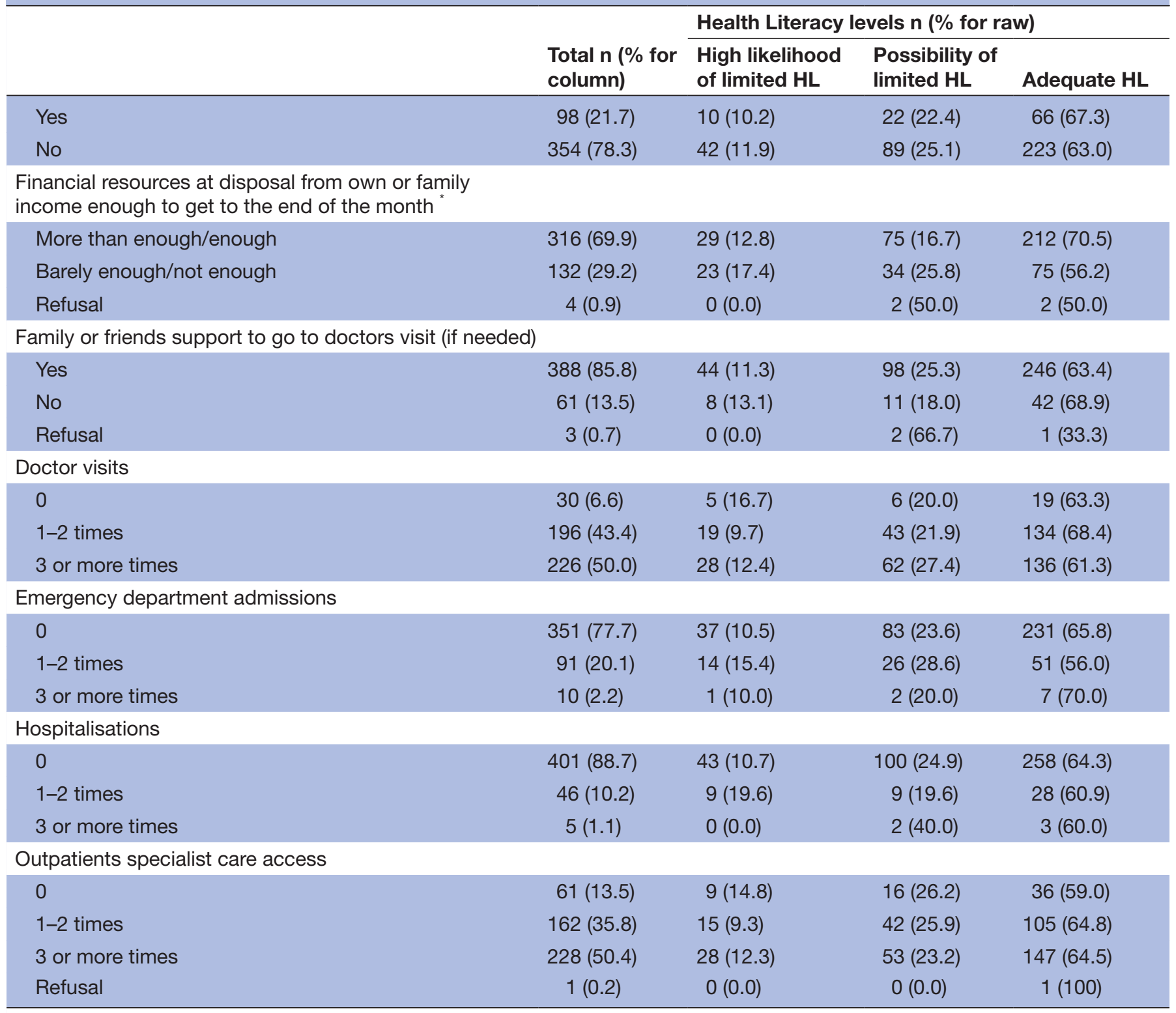

${ }^{*} \mathrm{P}<0.05$.

†Difference between $100 \%$ and the sum of the percentages of each variable corresponds to missing values.

$\mathrm{HL}$, health literacy.

presence of a high mean HL score in the population, and inadequate level of functional HL was present in a relatively small proportion of the population. According to multivariate analyses, the following antecedents resulted significantly associated with the level of functional HL: age, educational level and financial situation. As far as health outcomes are concerned, only self-reported health status resulted significantly associated with functional HL in the multivariate analysis.

To best of our knowledge, our study is the first that has set the assessment of functional HL with the NVS tool in a population-based sample as primary outcome in Italy. However, it should be pointed out that results of our study are based on a non-representative Italian population sample (a limitation described further below). In the literature, only Palumbo $e t a l^{29}$ in their study have used the NVS tool in a population-based sample in Italy; however in this study, the primary outcomes were to assess HL and its antecedents and consequences with HLS-EU-Q47 and NVS was used to check the validity of self-reported literacy skills (HLS-EU-Q47). As a result of this, several data of the NVS in the population are not reported (ie, NVS score) and it is not possible to compare our findings with this study.

In the literature, many studies have described several antecedents that may positively or negatively impact on HL; however to date, it is difficult to draw definitive conclusions on this topic as a variety of sampling frame, design and HL measures have been adopted in the literature. $^{6}$ Furthermore, demographic and socioeconomic 


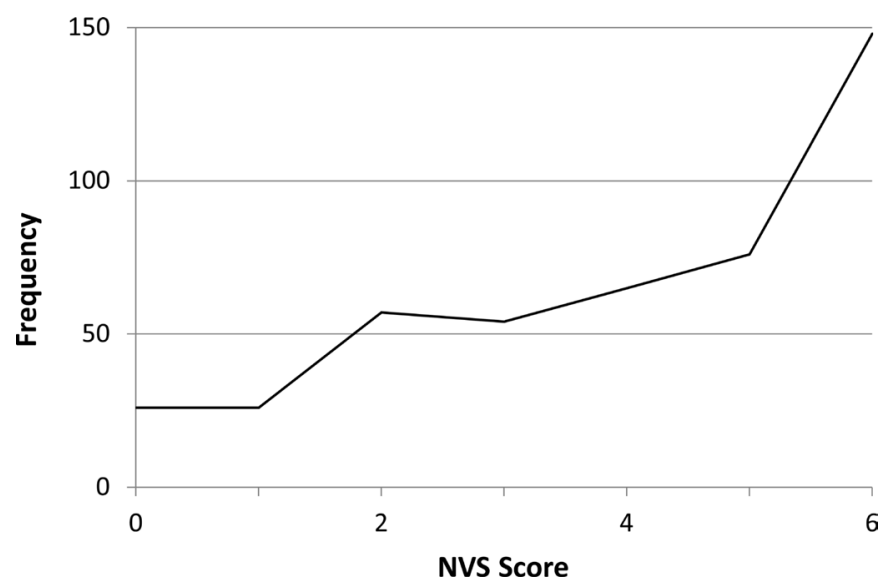

Figure 2 Distribution of Italian version of Newest Vital Sign (NVS-IT) score.

factors may impact differently on HL depending on the national and cultural contexts. ${ }^{5151630}$ In light of this, our findings on antecedents of functional HL contribute to the current debate in the literature, and may be considered as the first attempt to highlight the independent predictors of functional HL in the Italian context.

Age and education are reported to be important predictors of HL levels in the literature. ${ }^{51516}$ As far as education is concerned, in our study, a higher education level resulted to be independently associated with higher functional HL levels; on the contrary, having received training or being employed in the field of healthcare does not impact on functional HL level. As the NVS tool mainly measures document literacy and numeracy, these findings may suggest that these skills are mainly developed in the context of general education with little influence by further and more specific education. Regarding age, results showed a negative independent association with functional HL suggesting that as age increases, a diminished mental alertness and/or cognitive impairment (eg, memory-retrieval problems and inadequate numeracy) may play a crucial role in limiting the functional $\mathrm{HL}$

Table 3 Multivariate logistic regression analysis for antecedents of Health Literacy ( $\mathrm{HL}$ is the outcome variable)-final model

\begin{tabular}{llll}
\hline & OR & P value & $95 \%$ Cl \\
\hline Age & 1.07 & $<0.001$ & 1.05 to 1.09 \\
Education & & & \\
$\quad$ Bachelor's degree and higher & 1.000 & - & - \\
$\begin{array}{l}\text { High school graduates } \\
\begin{array}{l}\text { Less than a high school } \\
\text { diploma }\end{array}\end{array}$ & 2.01 & 0.004 & 1.53 to 3.61 \\
& & & \\
\end{tabular}

Financial situation

\begin{tabular}{llll} 
More than enough/enough & 1 & - & - \\
Barely enough/not enough & 1.639 & 0.041 & 1.17 to 2.63 \\
\hline
\end{tabular}

OR is calculated as 'inadequate and at-risk HL' vs 'adequate HL'. $n, 448$; pseudo $R^{2}=0.1404$.

$\mathrm{HL}$, health literacy.
Table 4 Multivariate logistic regression analysis with selfreported health status as the dependent variable-final model

\begin{tabular}{lcll}
\hline & OR & P value & $95 \% \mathbf{C l}$ \\
\hline Health Literacy & & & \\
$\quad \begin{array}{l}\text { Adequate HL } \\
\text { Inadequate and at-risk HL }\end{array}$ & 2.25 & 0.002 & 1.75 to 2.75 \\
Long-term illness & & & \\
\hline No & 1 & - & - \\
One & 4.04 & $<0.001$ & 3.46 to 4.62 \\
More than one & 12.78 & $<0.001$ & 12.1 to 13.45 \\
Financial situation & & & \\
$\quad \begin{array}{l}\text { More than enough/enough } \\
\text { Barely enough/not enough }\end{array}$ & 1 & - & - \\
\hline
\end{tabular}

OR is calculated as 'so-so/fair or bad health status' vs 'excellent, very good or good health status'.

$\mathrm{n}, 448$; pseudo $\mathrm{R}^{2}=0.1860$.

$\mathrm{HL}$, health literacy.

skills. Indeed, a recent study by Fawns-Ritchie $e t$ al argued that functional HL measures may, in part, assess fluidtype cognitive abilities; furthermore, Kobayashi et al found that age-related differences in functional HL skills are largely explained by cognitive ageing. ${ }^{31}{ }^{32}$ Further research on this topic suggested that educational differences may also influence age-related differences in functional HL skills as education has changed over the time. ${ }^{33}$ Considering that people with low education and older people have the highest burden of chronic diseases, ${ }^{34-37}$ and that these diseases require a broad range of reading and numeracy skills for their management, the described associations of functional HL with education and age highlight the need to design and implement health policies tailored on HL skills in these populations.

Our findings have also highlighted that a worse financial situation is associated with lower level of functional HL. Literature reports contrasting results concerning the association between socioeconomic status and HL measured through NVS score ${ }^{151621}$; however, these variables have been little investigated by population-based studies which also considered the measure of functional HL. Further studies are needed to elucidate the mechanisms underlying the relationship between socioeconomic status and HL.

Regarding health outcomes, self-reported health status was found to be significantly associated with functional $\mathrm{HL}$, and with financial situation and the presence of longterm illnesses. In the literature, the underlying mechanisms through which HL influences the health-related outcomes are not entirely known, and several theoretical models have been proposed to explain these mechanisms. ${ }^{68-40}$ However, none of these models have been fully validated, and further studies examining the mechanisms underlying the relationship between HL and health outcomes are needed. 
No other health outcomes were found to be significantly associated with functional HL in our study. Although several HL associations with health outcomes have been proposed in the literature, most of them have been evaluated in the clinical context and only few at the general population level. ${ }^{51617}$ Because NVS was primarily designed to detect illiteracy, it may show a ceiling effect when used in general populations. ${ }^{41}$ A ceiling effect occurs when a high proportion of participants in a study have maximum scores on the observed variable. This issue makes discrimination among participants among the top end of the scale impossible and may lead to attenuated or absent correlations between HL and other variables, ${ }^{42}$ as described also by other authors. ${ }^{43-45}$ In our sample, about $30 \%$ of the participants reported the higher score at the NVS-IT. For this reason, a more in-depth evaluation of the presence and effects of skewed distribution of NVS is needed in order to better adjust and calibrate this HL screening tool to use it appropriately in the general population, which in turn may permit to draw more robust conclusions on the presence and strengths of HL associations with health outcomes.

In this study, telephone interviews were used to collect NVS-IT data, while in almost all the studies face-to-face interviews were used. To date, to the best of our knowledge, our study is the first in reporting the comparison of NVS data collected using different methods of administration. The comparison of the NVS score between faceto-face and telephone interviews showed an excellent agreement with no significant difference between the NVS scores. Compared with face-to-face interviews, telephone interviews offer several advantages, ${ }^{46}$ in particular the elimination of any bias caused by the appearance of the interviewer. Furthermore, it should be pointed out that the application of NVS may cause stress and shame feelings in people with low numeracy/low literacy skills, possibly discouraging their participation in the interview. In this light, it may be argued that the willingness to participate in an interview that may cause shame and stress is higher if the interview is phone-administered. ${ }^{46}$ However, to the best of our knowledge, no studies have specifically compared the participation rates between telephone and face-to-face NVS interviews, and future research is needed to elucidate whether the telephone mode may encourage the participation of people with low literacy/numeracy skills in NVS interviews. On the other hand, the main potential risk with telephone interview compared with face-to face is that the respondent may seek help from another person at home; however, this risk is minor, ${ }^{46}$ since the interviewer would be able to notice the involvement of other people (ie, the person on the phone would have to repeat each question or use the hands-free mode).

This is the first study in Italy that comprehensively attempts to assess functional HL and its related antecedents and outcomes with NVS in a population-based sample. This consideration, together with the evaluation of various potential functional HL consequences, antecedents and confounding factors, should be considered as the strengths of this study.

Nevertheless, the study has several limitations. First, the population-based sample was obtained with a combination of convenience and probability sampling procedures. Thus, data cannot be considered representative of the overall Italian or Florentine adult population, and this is a major limitation for external comparison of the study results. Second, as the variables have been self-reported by the participants through interviews, the study may have suffered the recognised limitations of using this approach, such as recall or social desirability bias. ${ }^{46}$ However, the telephone interview may have limited this potential bias especially for those variables potentially more influenced by social desirability such as the BMI and socioeconomic status. As for recall bias, it should be underlined that the length of recall period for health services use (ie, last 12 months) may have affected the accuracy or completeness of the information retrieved from study participants, especially for GPs visits. This period was selected in order to allow for comparability with other studies. ${ }^{516}$ Third, results may have been influenced by a non-response bias, however the extent of this potential bias-if present-is limited as participants and non-participants showed only a small difference in the mean age: since participants were on average 2 years older than non-participants, the functional HL level resulted in our sample may be slightly lower than in the general population. Lastly, although participants were randomly selected from the registers of the GPs, the GPs were selected using a convenience criteria, which may have introduced a selection bias. However, it should be pointed out that the geographical coverage of the sample included residents of different areas of Florence as the selected GPs were based in different districts of the city.

\section{CONCLUSION}

Our study is the first in measuring the functional HL with NVS tool and its associations with antecedents and consequences at population level in Italy. Our findings highlighted the presence of good level of functional HL in the population compared with the European Union average. However, older, less educated and poorer population groups resulted at higher risk of limited or inadequate functional HL. These results suggest the need to design and implement health policies and interventions tailored on different HL levels in order to allow the more vulnerable population groups to better cope with the health challenges. As far as health outcomes are concerned, only self-reported health status was found to be significantly associated with functional HL among the considered health outcomes. The underlying mechanisms through which HL influences the health-related outcomes are not entirely known and a more in-depth evaluation of these relationships are needed. As NVS test was originally developed in the clinical context, a ceiling effect that may skew the HL levels distribution in the population may occur 
when NVS is used at the general population level, ultimately leading to attenuated correlation between HL and its potential predictors and consequences. Further studies investigating the presence and effects of this ceiling effect are needed in order to confirm the validity or better calibrate the NVS tool for the general population studies and to draw more robust conclusions on the presence and strengths of functional HL associations.

Acknowledgements The authors would like to thank Drs Flavio Godi, Mauro Grazini and Poste Italiane for their assistance in the study implementation and conduct. The authors would also like to thank the subjects whose participation made this study possible.

Collaborators Florence Health Literacy Research Group: Elisabetta Alti, Sergio Baglioni, Angela Bechini, Leonardo Bellino, Niccolò Berzi, Jacopo Bianchi, Sara Boccalini, Guglielmo Bonaccorsi, Giuseppe Burgio, Alessandro Bussotti, Marco Del Riccio, Martina Donzellini, Angela Galdiero, Alessandro Grassi, Tommaso Grassi, Vieri Lastrucci, Arrigo Lombardi, Chiara Lorini, Sarah Mantwill, Federico Manzi, Alessandro Mereu, Donatella Messina, Chiara Milani, Diana Paolini, Marco Targonato, Marco Toccafondi, Gino Sartor, Virginia Vettori.

Contributors GB: conception and design; drafted the article; gave final approval of the version to be submitted. VL: conception and design; data collection; data interpretation; drafted the article; gave final approval of the version to be submitted; final preparation and submission. W: conception and design; data collection; data interpretation; drafted the article; gave final approval of the version to be submitted. $\mathrm{CL}$ : conception and design; data analysis and interpretation; drafted the article; gave final approval of the version to be submitted. FHLRG: conception and design; data collection; gave final approval of the version to be submitted.

Funding The authors have not declared a specific grant for this research from any funding agency in the public, commercial or not-for-profit sectors.

\section{Competing interests None declared.}

Ethics approval The study was approved by the Ethics Committee of the 'Area Vasta Centro' (Local Health Unit of Central Tuscany, Careggi University Hospital and Meyer University Children's Hospital; Ref. CEAVC:10113, 1 December 2016).

Provenance and peer review Not commissioned; externally peer reviewed.

Data sharing statement The dataset generated and analysed during the current study is available from the corresponding author on reasonable request.

Open access This is an open access article distributed in accordance with the Creative Commons Attribution Non Commercial (CC BY-NC 4.0) license, which permits others to distribute, remix, adapt, build upon this work non-commercially, and license their derivative works on different terms, provided the original work is properly cited, appropriate credit is given, any changes made indicated, and the use is non-commercial. See: http://creativecommons.org/licenses/by-nc/4.0/.

\section{REFERENCES}

1. Kickbush I, Maag D. Health Literacy. In: Heggenhougen K, Quah S, eds. International encyclopedia of public health volume 3. San Diego, CA: Academic Press, 2008:204-11.

2. World Health Organisation Regional Office for Europe. Health 2020. A european policy framework supporting action across government and society for health and well-being. Copenhagen: World Health Organisation Regional Office for Europe, 2012.

3. European Commission. Together for health. A Strategic approach for the EU 2008-2013. COM(2007) 630 final. Brussels: European Commision, 2007.

4. Berkman ND, Sheridan SL, Donahue KE, et al. Low health literacy and health outcomes: an updated systematic review. Ann Intern Med 2011;155:97-107.

5. HLS-EU Consortium. Comparative report on health literacy in eight EU member states. The European health literacy survey HLS-EU. 2012 http://ec.europa.eu/chafea/documents/news/Comparative_ report_on_health_literacy_in_eight_EU_member_states.pdf

6. Sørensen K, Van den Broucke S, Fullam J, et al. Health literacy and public health: a systematic review and integration of definitions and models. BMC Public Health 2012;12:80.

7. Altin SV, Finke I, Kautz-Freimuth S, et al. The evolution of health literacy assessment tools: a systematic review. BMC Public Health 2014;14:1207.
8. Nguyen TH, Paasche-Orlow MK, McCormack LA. The State of the Science of Health Literacy Measurement. Stud Health Technol Inform 2017;240:189-203

9. Weiss BD, Mays MZ, Martz W, et al. Quick assessment of literacy in primary care: the newest vital sign. Ann Fam Med 2005;3:514-22.

10. Osborn CY, Weiss BD, Davis TC, et al. Measuring adult literacy in health care: performance of the newest vital sign. Am J Health Behav 2007;31(Suppl 1):36-46.

11. Shah LC, West $P$, Bremmeyr K, et al. Health literacy instrument in family medicine: the "newest vital sign" ease of use and correlates. $J$ Am Board Fam Med 2010;23:195-203.

12. Powers BJ, Trinh JV, Bosworth HB. Can this patient read and understand written health information? JAMA 2010;304:76-84.

13. Strijbos RM, Hinnen JW, van den Haak RFF, et al. Inadequate health literacy in patients with arterial vascular disease. Eur J Vasc Endovasc Surg 2018;56:239-45.

14. Batterham RW, Hawkins M, Collins PA, et al. Health literacy: applying current concepts to improve health services and reduce health inequalities. Public Health 2016;132:3-12.

15. Paiva D, Silva S, Severo $M$, et al. Limited health literacy in portugal assessed with the newest vital sign. Acta Med Port 2017;30:861-9

16. Adams RJ, Appleton SL, Hill CL, et al. Risks associated with low functional health literacy in an Australian population. Med J Aust 2009;191:530-4.

17. Rowlands G, Protheroe J, Winkley J, et al. A mismatch between population health literacy and the complexity of health information: an observational study. Br J Gen Pract 2015;65:e379-86.

18. Capecchi L, Guazzini A, Lorini C, et al. The first italian validation of the most widespread health literacy assessment tool: the Newest Vital Sign. Epidemiol Prev 2015;39(4 Suppl 1):124-8.

19. Bonaccorsi G, Grazzini M, Pieri L, et al. Assessment of Health Literacy and validation of single-item literacy screener (SILS) in a sample of Italian people. Ann Ist Super Sanita 2017;53:205-12.

20. Zotti P, Cocchi S, Polesel J, et al. Cross-cultural validation of health literacy measurement tools in Italian oncology patients. BMC Health Serv Res 2017;17:410.

21. Barber MN, Staples M, Osborne RH, et al. Up to a quarter of the Australian population may have suboptimal health literacy depending upon the measurement tool: results from a population-based survey. Health Promot Int 2009;24:252-61.

22. Lorini C, Santomauro F, Grazzini M, et al. Health literacy in Italy: a cross-sectional study protocol to assess the health literacy level in a population-based sample, and to validate health literacy measures in the Italian language. BMJ Open 2017;7:e017812.

23. Lorini C, Lastrucci V, Mantwill S, et al. Measuring health literacy in Italy: a validation study of the HLS-EU-Q16 and of the HLS-EU-Q6 in Italian language, conducted in Florence and its surroundings. Ann Ist Super Sanita 2019;55:10-8.

24. Toçi E, Burazeri G, Myftiu S, et al. Health literacy in a populationbased sample of adult men and women in a South Eastern European country. J Public Health 2016;38:6-13.

25. Park MS, Kang KJ, Jang SJ, et al. Evaluating test-retest reliability in patient-reported outcome measures for older people: A systematic review. Int J Nurs Stud 2018;79:58-69.

26. Bujanga MA, Baharum N. Guidelines of the minimum sample size requirements for Cohen's Kappa. Epidemiology Biostatistics and Public Health 2017:e12267.

27. Bujanga MA, Baharum N. A simplified guide to determination of sample size requirements for estimating the value of intraclass correlation coefficient: a review. Arch Orofac Sci 2017;12:1-11.

28. Guidelines CDV. criteria, and rules of thumb for evaluating normed and standardized assessment instruments in psychology. Psychological Assessment 1994;6:284-90.

29. Palumbo R, Annarumma C, Adinolfi $P$, et al. The Italian health literacy project: insights from the assessment of health literacy skills in Italy. Health Policy 2016;120:1087-94.

30. Bakker CJ, Koffel JB, Theis-Mahon NR. Measuring the health literacy of the Upper Midwest. J Med Libr Assoc 2017;105:34-43.

31. Fawns-Ritchie C, Starr JM, Deary IJ. Role of cognitive ability in the association between functional health literacy and mortality in the Lothian Birth Cohort 1936: a prospective cohort study. BMJ Open 2018;8:e022502

32. Kobayashi LC, Smith SG, O'Conor R, et al. The role of cognitive function in the relationship between age and health literacy: a cross-sectional analysis of older adults in Chicago, USA. BMJ Open 2015;5:e007222.

33. Morrow D, Clark D, Tu W, et al. Correlates of health literacy in patients with chronic heart failure. Gerontologist 2006;46:669-76.

34. GBD 2016 Causes of Death Collaborators. Global, regional, and national age-sex specific mortality for 264 causes of death, 1980- 
2016: a systematic analysis for the Global Burden of Disease Study 2016. Lancet 2017;390:1151-210.

35. Steenland K, Henley J, Thun M. All-cause and cause-specific death rates by educational status for two million people in two American Cancer Society cohorts, 1959-1996. Am J Epidemiol 2002;156:11-21.

36. Qureshi Al, Suri MF, Saad M, et al. Educational attainment and risk of stroke and myocardial infarction. Med Sci Monit 2003;9:CR466-73.

37. Silventoinen K, Pankow J, Jousilahti P, et al. Educational inequalities in the metabolic syndrome and coronary heart disease among middle-aged men and women. Int J Epidemiol 2005;34:327-34.

38. Nutbeam D. Health literacy as a public health goal: a challenge for contemporary health education and communication strategies into the 21st century. Health Promot Int 2000;15:259-67.

39. Paasche-Orlow MK, Wolf MS. The causal pathways linking health literacy to health outcomes. Am J Health Behav 2007;31(Suppl 1):19-26.

40. von Wagner C, Steptoe A, Wolf MS, et al. Health literacy and health actions: a review and a framework from health psychology. Health Educ Behav 2009;36:860-77.
41. Reeve CL, Basalik D. Is health literacy an example of construct proliferation? A conceptual and empirical evaluation of its redundancy with general cognitive ability. Intelligence 2014:44:93-102.

42. Fransen MP, Van Schaik TM, Twickler TB, et al. Applicability of internationally available health literacy measures in the Netherlands. $J$ Health Commun 2011;16(Suppl 3):134-49.

43. Lindau ST, Tomori C, Lyons T, et al. The association of health literacy with cervical cancer prevention knowledge and health behaviors in a multiethnic cohort of women. Am J Obstet Gynecol 2002;186:938-43.

44. Okamoto M, Kyutoku Y, Sawada M, et al. Health numeracy in Japan: measures of basic numeracy account for framing bias in a highly numerate population. BMC Med Inform Decis Mak 2012;12:104.

45. Suka M, Odajima T, Okamoto $M$, et al. Relationship between health literacy, health information access, health behavior, and health status in Japanese people. Patient Educ Couns 2015;98:660-8.

46. Streiner DL, Norman GR. Health measurement scales. A practical guide to their development and use. Oxford University Press: Oxford, 2008. 